\title{
Traumatic and non-traumatic spinal cord impairment in New Zealand: incidence and characteristics of people admitted to spinal units
}

\author{
Sarah Derrett, ${ }^{1}$ Carolyn Beaver, ${ }^{2}$ Martin J Sullivan, ${ }^{3}$ G Peter Herbison, ${ }^{1}$ Rick Acland, ${ }^{4}$ \\ Charlotte Paul ${ }^{1}$
}

${ }^{1}$ Department of Preventive and Social Medicine, Dunedin School of Medicine, University of Otago, Dunedin, New Zealand ${ }^{2}$ Burwood Academy of Independent Living (BAIL), Christchurch, New Zealand ${ }^{3}$ School of Health and Social Services, Massey University, Palmerston North, New Zealand ${ }^{4}$ Burwood Hospital Spinal Unit, Canterbury District Health Board, Christchurch, New Zealand

\section{Correspondence to} Dr Sarah Derrett, Injury Prevention Research Unit, Department of Preventive and Social Medicine, Dunedin School of Medicine, PO Box 56, University of Otago, Dunedin 9056, New Zealand; sarah.derrett@otago.ac.nz

Accepted 7 March 2012

Published Online First 29 April 2012

\section{ABSTRACT}

This paper estimates the incidence (all ages) of spina cord neurological impairment (SCl; traumatic and nontraumatic) in New Zealand and describes pre-SCl characteristics and early post-SCI outcomes for participants (16-64 years) in this longitudinal study. Demographic and clinical data on all people admitted to New Zealand's two spinal units (mid-2007 to mid-2009) were included for the estimate of incidence. Participants in this longitudinal study were asked at first interview about pre-SCI socio-demographic, health and behavioural characteristics, and about post-SCI symptoms, general health status (EQ-5D) and disability (WHODAS 12-item). Age-adjusted incidence rates (95\% CI) for European, Māori, Pacific and 'Other' ethnicities were 29 (24-34), 46 (30-64), $70(40-100)$ and $16(9-22)$ per million, respectively. Interviews with 118 (73\%) participants (16-64 years), occurred 6.5 months post-SCl. Most reported bother with symptoms, and problems with health status and disability. Compared with Europeans, the incidence of SCl is high among Māori and particularly high among Pacific people. Six months after SCl, proximate to discharge from the spinal units, considerable symptomatic, general health and disability burden was borne by people with SCl.

\section{INTRODUCTION}

A longitudinal cohort study of people with spinal cord neurological impairment (SCI) in New Zealand is underway. ${ }^{1}$ New Zealand has no SCI register, and little is known about people with SCI in New Zealand-despite previously reported high rates of traumatic SCI and the impact on individuals and their families. ${ }^{1} 2$

This paper aims to: (1) estimate SCI incidence, for all ages, from a 'census' overview between 28 July 2007 and 6 August 2009; (2) describe characteristics of people admitted to either of $\mathrm{New}$ Zealand's two spinal units with SCI; (3) describe pre-SCI characteristics of participants in the longitudinal study (ages 16-64 years); (4) describe their early post-SCI symptoms, health and disability; and (5) explain modifications to our previously published protocol. ${ }^{1}$

\section{METHODS}

Demographic and clinical data on all people (all ages), admitted during the study period to either of New Zealand's two spinal units for the first time following acute impairment, were included for the estimate of incidence. Denominator data were obtained from Statistics New Zealand, 2006 Census. $^{3}$

The longitudinal study aims to investigate how entitlement to rehabilitation and compensation affects socioeconomic and health outcomes for working-age people potentially able to access earnings-related compensation or invalid's benefits. ${ }^{1}$ Therefore, the longitudinal study recruited people aged 16-64 years, admitted to either spinal unit with SCI during a 2-year period. People were ineligible for the longitudinal study if the multidisciplinary clinical team identified: cognitive or communication problems precluding an interview, prognosis of likely death within 6 months, other diagnoses precluding interview (eg, active psychotic disorder); they were not New Zealand residents; or they had no neurological damage at time of recruitment.

Nurses collected demographic and clinical information from clinical records of people admitted with SCI, and approached potential participants about the study. Contact details of consenting people were provided to our team, and interviewers scheduled a first interview, intended to occur 4 months after the date of SCI.

Nurse-collected data included: dates of birth, SCI and admission; unit (Auckland or Burwood), sex, ethnicity and the ASIA Impairment Scale (AIS) grade. $^{4}$

At interview, participants were asked about preSCI socio-demographic characteristics using questions from the 2006 Census. ${ }^{3}$ People were asked their personal income in the year before SCI, and rated their "material standard of living'. 5 Participants reported their pre-SCI 'health in general'. ${ }^{6}$ The EQ-5D measured general health status the day before SCI along five dimensions (mobility, selfcare, usual activities, pain/discomfort, anxiety/ depression), each with three response options-no/ some/extreme problems; the last two grouped as 'Any Problems' for analysis. ${ }^{7}$ We asked an additional question about cognition ('intellectual activities such as remembering, concentrating, thinking and solving day to day problems'). ${ }^{8}$ People were asked about episodes, spanning 2 weeks or more in the year before SCI, when nearly every day they felt sad, blue or depressed, or lost interest in work or hobbies, or things they usually like to do for fun. ${ }^{89}$ Affirmative responses were classified as 'depressive mood'. Pre-SCI health-related disability was assessed by questions about health problems or conditions (lasting 6 months or more) that caused people difficulty with, or stopped them: doing injuryprevention.bmj.com/site/ about/unlocked.xhtml 
everyday activities; communicating, mixing with others or socialising; or any other activity people their age could usually do. ${ }^{3}$ People reporting difficulty with any item were categorised-'Yes disability'. Questions about cigarette smoking were from the Census. ${ }^{3}$ Alcohol use in the year before SCI was assessed using the AUDIT- $\mathrm{C}^{10}$; illicit drug use by asking if: marijuana/cannabis or other recreational drugs such as $\mathrm{P}$ (methamphetamine), speed, ecstasy, LSD, or cocaine were used in the year before SCI.

Participants were asked about SCI and post-SCI characteristics including: SCI cause, wheelchair use and place of residence. Post-SCI EQ-5D health status and symptom bother (derived from the Secondary Complications Survey) was collected. ${ }^{11}$ Post-SCI disability was measured using the WHODAS II 12-item which assesses activity limitations and participation restrictions over the past 30 days with five responses ('no/mild/moderate/ severe/extreme or cannot do' difficulty) for each item. ${ }^{12} 13$

\section{RESULTS}

Over two-years, clinical data were obtained for 238 people admitted to the two spinal units. Eight people were non-residents. Based on the remaining 230 residents, the estimated annual incidence rate (and 95\% CI) of SCI in New Zealand was 30 (26-34) per million. Age-adjusted (to the total New Zealand population) incidence rates for European, Māori, Pacific, and 'Other' ethnicities were 29 (24-34), 46 (30-64), 70 (40-100) and $16(9-22)$ per million, respectively.

For the longitudinal study, 76 were ineligible $(10$ aged $<16$ years, 42 aged $>64$ years, 7 unable to communicate, 3 the multidisciplinary clinical team advised no approach, 1 person died, 8 non-residents, 3 no neurological damage, 2 prognosis $<6$ months). Of the 162 eligible people, 118 participated (response rate $=73 \%$ ); 15 declined and 29 were non-contactable by interviewers following multiple contact attempts. ${ }^{14}$ Telephone $(62 \%)$, or in-person interviews, occurred 6.5 months (median) after SCI (IOR: 4.8-7.6).

No statistically significant differences in age, sex, unit or AIS grade were observed between participants and non-participants (table 1). Fewer Māori and Pacific people participated according to ethnicity collected from their clinical record. At interview we collected self-reported ethnicity; six additional people identified as Māori ( $\mathrm{n}=23 ; 19 \%)$. Pre-SCI characteristics are presented in table 2 . For the $80(68 \%)$ reporting income, median income was NZD\$50 000 (IOR NZD\$32 500-\$81 000).

The reported cause of SCI and early outcomes are presented descriptively in table 3. Injury was the reported cause of SCI for most (87\% for Māori, 60\% for Pacific and 77\% for non-Māori/ non-Pacific ethnicities). Bother with listed symptoms was reported by more than half. Participants also reported bother with 'other' symptoms, including: temperature regulation, generalised pain, numbness and pressure areas. Most reported post-SCI problems with EQ-5D health status and moderate-to-extreme difficulty with seven of the 12 WHODAS items.

\section{DISCUSSION}

The annual incidence of SCI (traumatic and non-traumatic) in New Zealand of 30 per million was the same as the mean in a recent worldwide review. ${ }^{15}$ A systematic review based on 13 studies showed a range of incidence rates for traumatic SCI from 12.1 to 57.8 per million. ${ }^{16}$ An earlier study in New Zealand of SCI found a much higher incidence (49 per million), even though it did not include non-traumatic cases. ${ }^{2}$ It is likely that different methods of case ascertainment explains some of this difference
Table 1 Characteristics collected from clinical records for those eligible for the longitudinal SCI study

\begin{tabular}{|c|c|c|c|}
\hline Characteristics & $\begin{array}{l}\text { Participants } \\
(\mathrm{n}=118) \\
\mathrm{n}(\%)\end{array}$ & $\begin{array}{l}\text { Non-participants } \\
(\mathrm{n}=44) \\
\mathrm{n}(\%)\end{array}$ & p-Value \\
\hline \multicolumn{4}{|l|}{ Age (years) } \\
\hline $16-24$ & $21(18)$ & $14(32)$ & \\
\hline $25-34$ & $21(18)$ & $9(20)$ & \\
\hline $35-44$ & $24(20)$ & $11(25)$ & \\
\hline $45-54$ & $28(24)$ & $8(18)$ & \\
\hline $55-64$ & $24(20)$ & $2(5)$ & 0.067 \\
\hline \multicolumn{4}{|l|}{ Sex } \\
\hline Male & $90(76)$ & $34(77)$ & \\
\hline Female & $28(24)$ & $10(23)$ & 0.894 \\
\hline \multicolumn{4}{|l|}{ Spinal unit } \\
\hline Auckland Spinal Unit & $59(50)$ & $23(52)$ & \\
\hline Burwood Spinal Unit & $59(50)$ & $21(48)$ & 0.797 \\
\hline \multicolumn{4}{|l|}{ AIS grade } \\
\hline A & $36(31)$ & $14(32)$ & \\
\hline B & $9(8)$ & $2(5)$ & \\
\hline C & $10(9)$ & $4(9)$ & \\
\hline D & $63(53)$ & $24(55)$ & 0.921 \\
\hline \multicolumn{4}{|l|}{ Ethnicity } \\
\hline New Zealand European & 77 (65) & $21(48)$ & \\
\hline Māori & $17(14)$ & $12(27)$ & \\
\hline Pacific* & $10(8)$ & $8(18)$ & \\
\hline Other & $14(12)$ & $3(9)$ & 0.044 \\
\hline
\end{tabular}

Both spinal units have similar rehabilitation programmes in place. Patients are not denied access to the units - although there may be delays in admission if the units are full. The Auckland Spinal Unit accepts patients after they have mobilised (eg, to a wheelchair) in the referring hospital, and has an average length of stay 2 weeks shorter than the Burwood Spinal Unit which is involved in patients' care from day 1. The Auckland Spinal Unit $(20$ beds) accepts patients from the upper half of the North Island; the Burwood Spinal Unit (28 beds) from the rest of New Zealand.

*Pacific ethnicity=Pacific groups as stated in the New Zealand Census (ie, Samoan, Cook Island Māori, Tongan and Niuean).

AIS, ASIA Impairment Scale; SCI, spinal cord neurological impairment.

(the earlier study used all hospital admissions for SCI with and without evidence of vertebral fracture). In our study, people in the acute phase would have been excluded from our study if they died before admission to a spinal unit. On the other hand, the earlier study found only $8 \%$ were complete SCI lesions, compared with 32\% for the 16-64 years subgroup in our report. People with minimal neurological impairment and people with terminalcancer-related SCI requiring palliative treatment prior to dying, are less likely to be admitted to a spinal unit. Given these differences in ascertainment, no conclusion can be drawn about changes in rates over time. Nevertheless, rates of SCI remain elevated among Māori (as the earlier study found) and a marked elevation was observed among Pacific people (2.4 times the European rate).

Results from the longitudinal study provide the first overview of people with SCI aged between 16 and 64 years admitted to New Zealand's spinal units. Participants differed from nonparticipants in relation to ethnicity only; when self-reported ethnicity was asked, the proportion reporting Māori ethnicity met our prior expectations. ${ }^{1}$ Fewer participants reported nontraumatic SCI than anticipated. This may be because our participants were aged 16-64 years, and non-traumatic SCI increases with age. People were interviewed slightly later than planned because of participants' preferences, interviewers' health and difficulty locating some participants following discharge. A range of pre-SCI characteristics were apparent. Six months after SCI, a large proportion experienced problems with symptoms, health status and disability.

A limitation of the study was the necessity for participants to 'recall' their pre-SCI health characteristics; collection of health 
Table 2 Pre-SCl characteristics of longitudinal study participants $(n=118)$

\begin{tabular}{|c|c|}
\hline Pre-injury characteristics & n (\%) \\
\hline \multicolumn{2}{|l|}{ Socio-demographic } \\
\hline \multicolumn{2}{|l|}{ Educational qualifications } \\
\hline None & $34(30)$ \\
\hline School & $22(19)$ \\
\hline Post-secondary school & $58(51)$ \\
\hline Missing & 4 \\
\hline \multicolumn{2}{|l|}{ Paid employment } \\
\hline$\geq 30 \mathrm{~h}$ per week & $91(77)$ \\
\hline$<30 \mathrm{~h}$ per week & $6(5)$ \\
\hline Not in paid employment & $21(18)$ \\
\hline \multicolumn{2}{|l|}{ Income (NZD\$1000s) } \\
\hline$\leq 30$ & $19(24)$ \\
\hline$>30 \leq 50$ & $24(30)$ \\
\hline$>50 \leq 80$ & $17(21)$ \\
\hline$>80$ & $20(25)$ \\
\hline Missing & 38 \\
\hline \multicolumn{2}{|l|}{ Standard of living } \\
\hline High & $30(26)$ \\
\hline Fairly high & $30(26)$ \\
\hline Medium & $45(40)$ \\
\hline Fairly low & $7(6)$ \\
\hline Low & $2(2)$ \\
\hline Missing & 4 \\
\hline \multicolumn{2}{|c|}{ General health, disability and behaviour } \\
\hline \multicolumn{2}{|l|}{ General health } \\
\hline Excellent & $47(40)$ \\
\hline Very good & $42(36)$ \\
\hline Good & $20(17)$ \\
\hline Fair & $8(7)$ \\
\hline Poor & $1(1)$ \\
\hline \multicolumn{2}{|c|}{ EQ-5D health status (any problems) } \\
\hline Mobility & $12(10)$ \\
\hline Self-care & $3(3)$ \\
\hline Usual activities & $8(7)$ \\
\hline Pain or discomfort & $22(19)$ \\
\hline Anxiety or depression & $14(12)$ \\
\hline (Cognition) & $11(9)$ \\
\hline \multicolumn{2}{|c|}{ Depressive episode in past year } \\
\hline Yes & $24(20)$ \\
\hline No & $94(80)$ \\
\hline \multicolumn{2}{|l|}{ Prior disability } \\
\hline Yes & $16(14)$ \\
\hline No & $102(86)$ \\
\hline \multicolumn{2}{|l|}{ Cigarette smoking } \\
\hline Current & $32(27)$ \\
\hline Past & $32(27)$ \\
\hline No & $53(45)$ \\
\hline Missing & $1(1)$ \\
\hline \multicolumn{2}{|l|}{ Alcohol use (AUDIT-C)* } \\
\hline Low use & $49(42)$ \\
\hline Moderate use & $41(35)$ \\
\hline High use & $28(24)$ \\
\hline \multicolumn{2}{|l|}{ Illicit substance use } \\
\hline Yes & $31(26)$ \\
\hline No & $87(74)$ \\
\hline
\end{tabular}

status prospectively would require a nation-wide observational study with regular measurement points until the sub-group people experienced SCI. Other studies have found injured peoples' recalled pre-injury health status approximates their
Table 3 Participants' ( $n=118)$ SCl-related and post-SCl outcomes (median 6.5 months after SCI)

\begin{tabular}{|c|c|}
\hline Post-SCI characteristic & n (\%) \\
\hline \multicolumn{2}{|l|}{ Self-reported cause of SCI } \\
\hline Injury cause of $\mathrm{SCl}$ & $91(77)$ \\
\hline IIlness cause of $\mathrm{SCl}$ & $24(20)$ \\
\hline Uncertain cause & $3(3)$ \\
\hline \multicolumn{2}{|l|}{ Wheelchair use } \\
\hline Yes & $59(50)$ \\
\hline Sometimes & $14(12)$ \\
\hline No & $45(32)$ \\
\hline \multicolumn{2}{|c|}{ Place of residence at time of interview } \\
\hline Original pre-SCI residence & $53(45)$ \\
\hline Still in spinal unit & $26(22)$ \\
\hline Temporary accommodation & $13(11)$ \\
\hline New permanent residence & $11(9)$ \\
\hline Missing or in transition & $15(13)$ \\
\hline \multicolumn{2}{|c|}{ EQ-5D health status (any problems) } \\
\hline Mobility & $109(92)$ \\
\hline Self-care & $78(66)$ \\
\hline Usual activities & $106(90)$ \\
\hline Pain or discomfort & $102(86)$ \\
\hline Anxiety or depression & $58(50)$ \\
\hline (Cognition) & $51(47)$ \\
\hline \multicolumn{2}{|c|}{ SCI-related symptom (any bother) } \\
\hline Leg swelling & $46(49)$ \\
\hline Leg spasm & $76(65)$ \\
\hline Shortness of breath & $30(26)$ \\
\hline Difficulty coughing & $35(30)$ \\
\hline Constipation & $66(57)$ \\
\hline Diarrhoea & $20(17)$ \\
\hline Indigestion & $20(17)$ \\
\hline Urinary tract infection & $33(28)$ \\
\hline Urinary incontinence & $34(29)$ \\
\hline Bladder management & $29(25)$ \\
\hline Headaches & $31(27)$ \\
\hline Back pain & $73(62)$ \\
\hline Shoulder pain & $56(48)$ \\
\hline Pain below SCI & $66(58)$ \\
\hline \multicolumn{2}{|c|}{ WHODAS (moderate, severe or extreme difficulties) } \\
\hline Standing long periods & $88(75)$ \\
\hline Household responsibilities & $78(67)$ \\
\hline Learning new task & $50(43)$ \\
\hline Community activities & $59(50)$ \\
\hline Emotionally affected & $67(57)$ \\
\hline Concentrating & $40(34)$ \\
\hline Walking a long distance & $93(79)$ \\
\hline Washing whole body & $60(51)$ \\
\hline Getting dressed & $58(49)$ \\
\hline Dealing with people & $28(24)$ \\
\hline Maintaining a friendship & $15(13)$ \\
\hline Day to day work & $76(64)$ \\
\hline
\end{tabular}

'recovered' health status, and that recall may be preferable to using general population norms as a proxy for pre-injury health. 1718

Strengths of our study include high participation rates, collection of a wide range of pre-SCI characteristics, and inclusion of people with traumatic and non-traumatic SCI. Our longitudinal study was funded within a (previous) Health Research Council of New Zealand grant aimed at developing New Zealand's research capacity among people with disability. The principal investigator (MS), study interviewers (including 


\section{What is already known on the subject}

- Internationally, spinal cord neurological impairment (SCI) incidence has been shown to range between 12.1 and 57.8 per million; no publications have reported the incidence of SCI in New Zealand during the past 18 years.

- SCl, with neurological impairment, can be costly to society and burdensome to individuals and their families (financially, socially and in terms of poor health and disability outcomes).

- Often, the focus of research has been on clinical or longerterm SCl outcomes; little appears to be known about outcomes of importance to people with $\mathrm{SCl}$, close to the time of discharge home.

\section{What this study adds}

The estimated incidence (and 95\% Cl) of SCl (traumatic and non-traumatic) in New Zealand is 30 (26-34) per million.

- Age-adjusted incidence rates were higher for Māori, and markedly higher for Pacific people, relative to Europeans.

- Considerable symptom, health and disability burdens are borne by people close to the time of discharge to the community from the spinal units.

CB), advisors and others, are people with SCI, as called for by people with SCI in the developmental phase of the project. ${ }^{1} 1920$

This brief paper highlights: current incidence rates (especially the high incidence among Pacific people which needs further investigation), and symptomatic, general health and disability burden borne by, and of importance to, people with SCI proximate to the time of discharge from the spinal units to the community. ${ }^{20}$

Some burden, such as bother with constipation and pain, may be amenable to improvement. Future analyses of longitudinal data will examine relationships between participants' baseline characteristics and longer-term outcomes.

Acknowledgements We are very grateful to all those who participated in this study. We thank: the past and present management team and staff at the Burwood Academy of Independent Living and the two spinal units (especially Dr Shridar Atresh, Dr Shaun Xiong, Marianne Cox, Julian Verkaaik and Mere Hibbs); the two nurses for the recruitment and clinical data collection-Karen Marshall (Clinical Nurse Specialist, Burwood Hospital Spinal Unit) and Karla Cooper (formerly of the Auckland Spinal Unit); and interviewers-Peina Tamou, Rob Courtney, and (the late) Pamela Fergusson; and especially Maureen Crawford the operational project coordinator. We also thank John Langley and Sue Wilson for their comments on an earlier draft of this paper.
Contributors SD and GPH had full access to the data in the study and take full responsibility for the integrity of the data. SD, GPH and CP analysed the data. MJS, $\mathrm{CP}, \mathrm{SD}$ and GPH contributed to the study design. CB undertook most of the interviews, SD led the preparation of the manuscript; all authors contributed to the interpretation of results and also to the review and editing of the manuscript.

Funding This study is funded by the Health Research Council of New Zealand. The views and conclusions expressed herein are the authors' and may not reflect those of the funders.

\section{Competing interests None.}

Ethics approval This study was undertaken following approval from the New Zealand Health and Disability Multi-Region Ethics Committee.

Provenance and peer review Not commissioned; externally peer reviewed.

Data sharing statement This is the first paper from a longitudinal study. The research team are currently involved in further analysis using the data.

\section{REFERENCES}

1. Sullivan M, Paul CE, Herbison GP, et al. A longitudinal study of the life Histories of people with spinal cord injury. Inj Prev 2010;16:1-9.

2. Dixon GS, Danesh JN, Caradoc-Davies TH. Epidemiology of spinal cord injury in New Zealand. Neuroepidemiology 1993;12:88-95.

3. Statistics New Zealand. 2006 Census Questionnaires. Statistics New Zealand 2006. http://www.stats.govt.nz/Census/about-2006-census/2006-censusquestionnaires.aspx (accessed 12 Aug 2011).

4. Kirshblum SC, Waring W, Biering-Sorensen F, et al. Reference for the 2011 revision of the international standards for neurological classification of spinal cord injury. J Spinal Cord Med 2011;34:547-54.

5. Ministry of Social Development. Survey of Working-Aged People in 2000. 2000 http://www.msd.govt.nz/aboutmsd-and-our-work/publications-resources/monitoring/ living-standards/living-standards-elsi.html (accessed 29 Sep 2011).

6. Ware J, Kosinski M, Gandek B. SF-36® Health Survey: Manual and Interpretation Guide. Lincoln, Rl: QualityMetric Incorporated, 2000.

7. Brooks R. Euro0ol: the current state of play. Health Policy 1996:37:53-72.

8. Langley J, Derrett S, Davie G, et al. A cohort study of short-term functional outcomes following injury: the role of pre-injury socio-demographic and health characteristics, injury and injury-related healthcare. Health Qual Life Outcomes 2011:9:68.

9. American Psychiatric Association Committee of Nomenclature and Statistics. Diagnostic and Statistical Manual of Mental Disorder-3rd Edition (DSM-3). Washington DC: American Psychiatric Association, 1980.

10. Bradley KA, DeBenedetti AF, Volk RJ, et al. AUDIT-C as a brief screen for alcoho misuse in primary care. Alcohol Clin Exp Res 2007:31:1208-17.

11. Dudley-Javoroski S, Shields RK. Assessment of physical function and secondary complications after complete spinal cord injury. Disabil Rehabil 2006;28:103-10.

12. Üstün T, Kostanjsek N, Chatterji S, et al, eds. Measuring Health and Disability: Manual for WHO Disability Assessment Schedule (WHODAS 2.0). Malta: WHO Press, 2010.

13. Andrews G, Kemp A, Sunderland M, et al. Normative data for the 12 item WHO disability assessment schedule 2.0. PLoS One 2009;4:e8343.

14. Morton LM, Cahill J, Hartge P. Reporting participation in Epidemiologic studies: a survey of practice. Am J Epidemiol 2006;163:197-203.

15. Wyndaele $\mathbf{M}$, Wyndaele JJ. Incidence, prevalence and epidemiology of spinal cord injury: what learns a worldwide literature survey? Spinal Cord 2006:44:523-9.

16. van den Berg ME, Castellote JM, de Pedro-Cuesta J, et al. Survival after spinal cord injury: a systematic review. J Neurotrauma 2010;27:1517-28.

17. Watson WL, Ozanne-Smith J, Richardson J. Retrospective baseline measurement of self-reported health status and health-related quality of life versus population norms in the evaluation of post-injury losses. Inj Prev 2007;13:45-50.

18. Wilson $\mathbf{R}$, Derrett $S$, Hansen $P$, et al. Retrospective recall versus population norms for the measurement of baseline health status. Personal Communication.

19. Sinnott K, Cassidy B, Nunnerley J, et al. Commentary on community participation following spinal cord injury in New Zealand. Top Spinal Cord Inj Rehabil 2010;15:63-71.

20. Hammell KR. Spinal cord injury rehabilitation research: patient priorities, current deficiencies and potential directions. Disabil Rehabil 2010;32:1209-18. 